\title{
Comparative Study On The Effect Of Some Histological Techniques On The Quantitative Morphometric Analysis
}

\author{
Bassem S. Kotb \\ Department of Histology, Faculty of Medicine - Al-Azhar University (Assuit)
}

\begin{abstract}
Quantitative morphometric studies are commonly used nowadays in histological and pathological labs and researches. The aim of the study was to evaluate the possible effect of the histological techniques on the morphometric results and determination of correction coefficients of morphometric parameters in dependence on the histological procedure used.

The organs and cells subjected to study were ; human RBCs (lack of nuclei), albino rats liver cells (active cells) and albino rat uterus (for gross study and its muscles and fibers content). Three techniques were selected; fresh cells (blood smear and liver cell print), frozen technique and paraffin sections fixed in neutral buffered formol (common histological technique). Quantitative morphometric analysis parameters selected were diameter, perimeter, area and area percent. The obtained results were statistically analyzed by using student paired t-Test. The study showed statistically significant changes in quantitative morphometric results under the effect of histological techniques used. Frozen technique increased the morphometric results, while paraffin technique decreased them when compared with those of fresh data. Also the morphometric data of gross area and perimeter of organs affected by their fibrous elements. The study concluded that all quantitative morphometric results must be corrected by a coefficient factor which depends on the organ and technique used before analysis and evaluation of data.
\end{abstract}

\section{Introduction}

In the last few years, as a result of introduction of computer vision (Image Analyzer), the quantitative histological techniques and interactive morphometry study becomes common on many histological and pathological research works.

The reproducibility of the measure ments depends on the tissue or cells and staining methods. A number of tech nical factors may cause random errors, such as quality of the slides, magnify ication, definition of the cells to be measured and measuring protocol.

Having quantified cell and tissue features, multivariate analysis may result in a better discrimination of two or more groups under study and can

provide important diagnostic and prognostic information.

Quantitation requires skill in object selection and the quality control of the whole measuring system. The use of quantitation as a black box can result in dramatic errors.

The quantitation subdivided into 3 subdivisions, morphometric analysis (e.g., count, distance, diameter, perime ter, area, area percent volume etc.,), color densitometric analysis (e.g., evaluation of histological stains, immuno-histological reactions or enzymatic activities colors as in depth or distribution) and the kinetic analysis (e.g., velocity, types of motion, amplitude, pattern of motion etc.). 


\section{Comparative Study On The Effect}

Tissue spread, frozen and paraffin techniques are commonly used for preparation of histological or patholo gical slides. In fresh unfixed histology cal sections (e.g., blood film, connective tissue spread, vaginal smear etc.,) direct analysis of cells may give more reliable information than from frozen or paraffin sections. Morphometric analysis of tissue or cells can be affected by various factors such as, change in temperature (as in freezing or paraffin sections), tissue water content (increased in frozen and low in paraffin techniques), or exposure to chemicals. The present study aimed to study the effect of histological techniques on the quantitative morphometric results.

\section{Materials and Methods}

The present study was done on human RBCs, adult albino rats hepatocyte, and adult albino rats uterus. Neutral buffered formol was used as a fixative. All paraffin and frozen sections were cut at 10 micrometers thickness. Hematoxyline and Eosin staining technique and Mallory trichrome stain were used in the study.(Drury and Wallington 1980).

\section{Study of human red blood corpuscles} diameters and areas:

- Ten fresh blood film were prepared by spread method without fixation, staining or mounting.

- Ten frozen and 10 paraffin slides were prepared from normal human full term placenta.
- Frozen and paraffin sections were stained, dehydrated, cleared and mounted in DPX.

Study of albino rats hepatocytes for cellular and nuclear diameters and areas:

- Ten fresh sections of hepatocytes were obtained by cell print method and stained without fixation, dehydration or mounting.

- Liver biopsy was taken for preparation of 10paraffin and another 10 section.

- Frozen and paraffin slides were stained, dehydrated, cleared and mounted.

Study of albino rat uterus for gross perimeter and area, uterine cavity (perimeter and area), and area percent of uterine collagen and muscle fibers.:

- Ten frozen and another 10 paraffin sections of uterus were prepared, stained, dehydrated, cleared and mounted in DPX.

The quantitative morphometric analysis studies were done by using SupeEye Image Analysis System - HeidiSoft Co. - Egypt. The obtained results were statistically analyzed by using pair student T-test.

\section{Results}

- Human red blood corpuscles morphometric results: are illustrated in Tables $1-2$ and Figures 1 to 3 and Figure 9.

(Table 1):The effect of histological techniques on the diameter of human RBCs

\begin{tabular}{|l|l|l|l|}
\hline & Fresh & Frozen & Paraffin \\
\hline Mean $(\mu \mathrm{m})$ & 6.84 & 7.50 & 5.47 \\
\hline SD & 0.67 & 0.51 & 0.73 \\
\hline SEM & 0.067 & 0.11 & 0.16 \\
\hline Min & 5.14 & 6.87 & 4.11 \\
\hline Max & 8.22 & 8.52 & 6.90 \\
\hline \multirow{2}{*}{ T-Test } & & Fresh vs. Frozen & Fresh vs. Paraffin \\
\cline { 4 - 4 } & & $5.59 \mathrm{E}-5$ & $5.69 \mathrm{E}-13$ \\
\cline { 4 - 4 } & & $\mathrm{p}<0.001$ & $\mathrm{p}<0.001$ \\
\cline { 4 - 4 } & & Sign. Inc. & Sign. Dec. \\
\cline { 3 - 4 } & & 8.85 & 20.04 \\
\hline Significance & & & \\
\hline Change $(\%)$ & & &
\end{tabular}




\section{Bassem S. Kotb}

* $\mathrm{SD}=$ Standard deviation

Min= Minimum value

T-Test=Student $\mathrm{t}$-Test (pair)

Sign. Inc. $=$ Significant increase

$\mathrm{NS}=$ Non significant change

Change $(\%)=\operatorname{abs}(100-($ Mean ValueXX / Mean Fresh value $) * 100)$

Table -2 The effect of histological techniques on the area of human RBCs

\begin{tabular}{|c|c|c|c|}
\hline & Fresh & Frozen & Paraffin \\
\hline $\operatorname{Mean}\left(\mu m^{2}\right)$ & 36.29 & 46.40 & 22.75 \\
\hline SD & 5.59 & 4.78 & 3.72 \\
\hline SEM & 1.25 & 1.07 & 0.83 \\
\hline Min & 26.13 & 38.33 & 16.60 \\
\hline $\operatorname{Max}$ & 44.27 & 53.460 & 31.03 \\
\hline \multirow{2}{*}{ T-Test } & & Fresh vs. Frozen & Fresh vs. Paraffin \\
\hline & & 3.6E-07 & $5.5 \mathrm{E}-11$ \\
\hline$p$-Value & & $p<0.001$ & $p<0.001$ \\
\hline Significance & & Sign. Increase & Sign. Decrease \\
\hline Change (\%) & & 27.86 & 37.30 \\
\hline
\end{tabular}

Figure - 1- Computerized photomicrograph of of normal human blood film

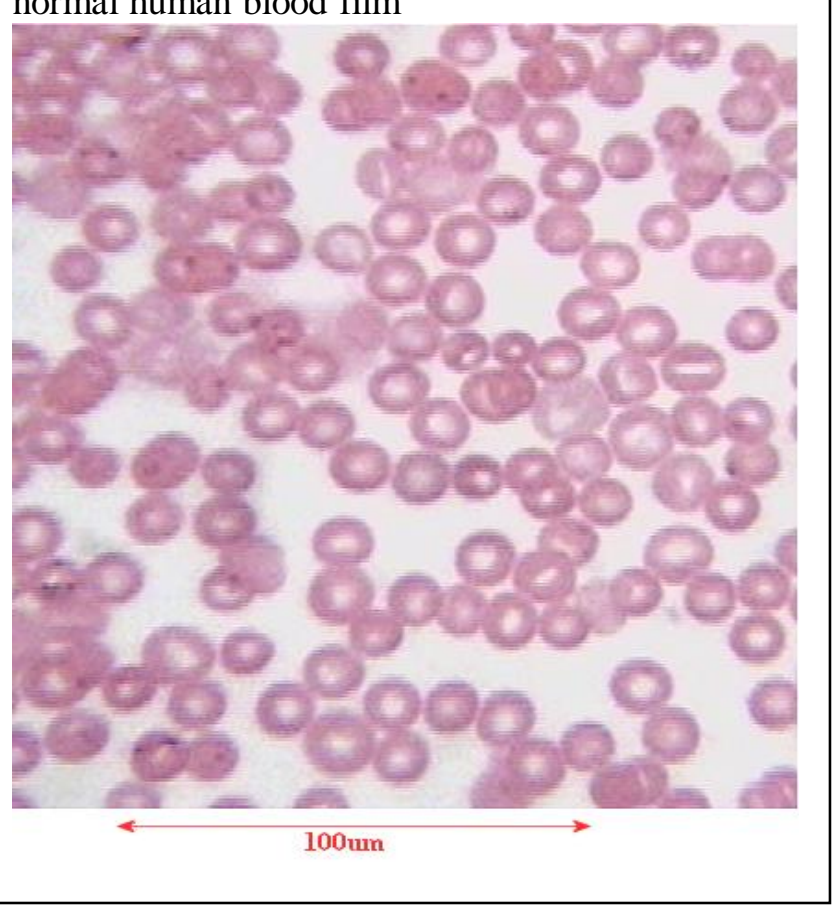

$\mathrm{SEM}=$ Standard error of mean

Max $=$ Maximum value

Significant $=p<0.05$

Sign. Dec. $=$ Significant decrease 


\section{Comparative Study On The Effect}

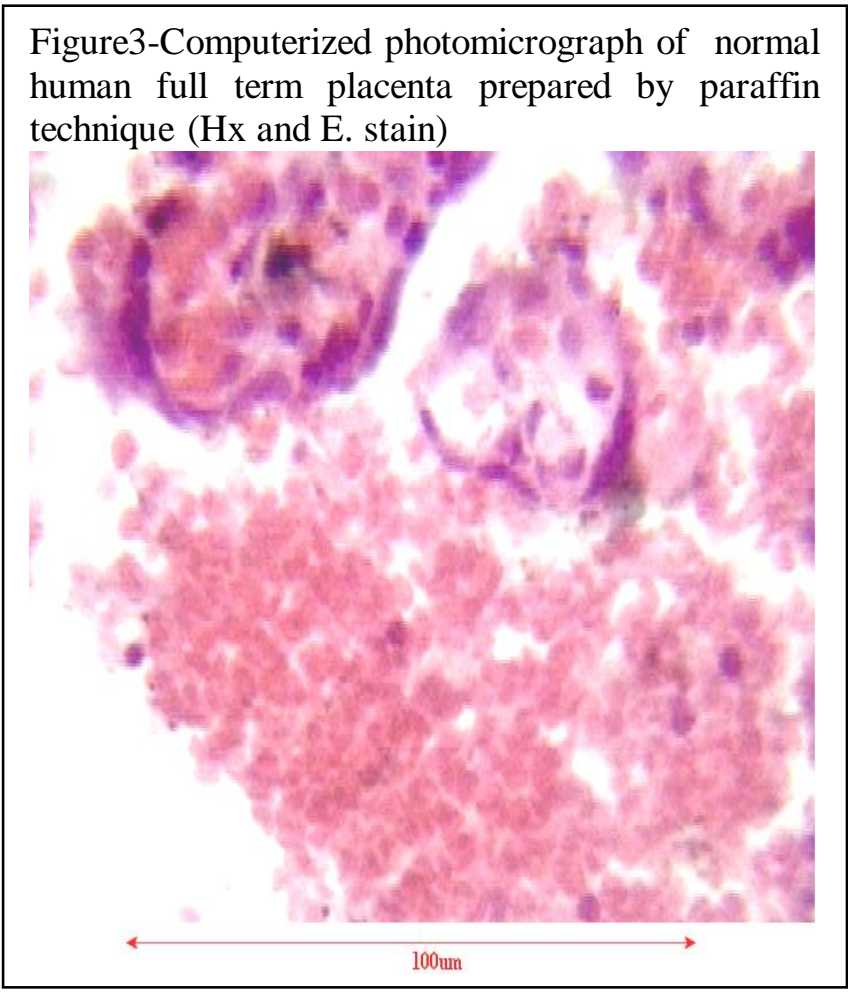

Figure 5-Computerized photomicrograph of adult albino rat hepatocytes prepared by frozen technique (Mallory trichrome stain)

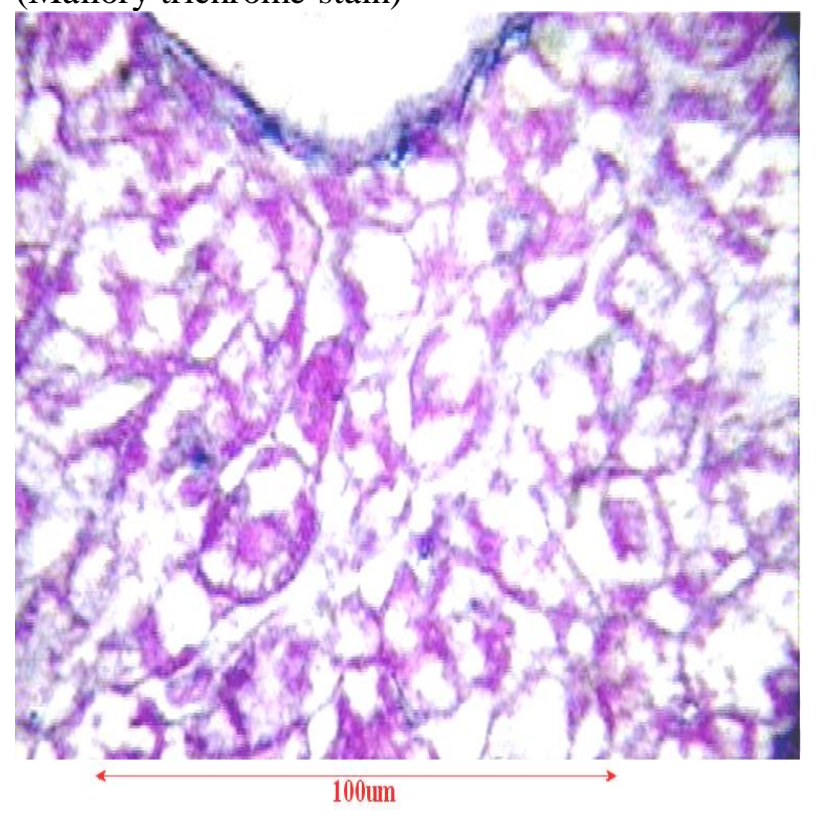

Figure 4-Computerized photomicrograph of adult albino rat hepatocytes prepared by cell print technique (Mallory trichrome stain)

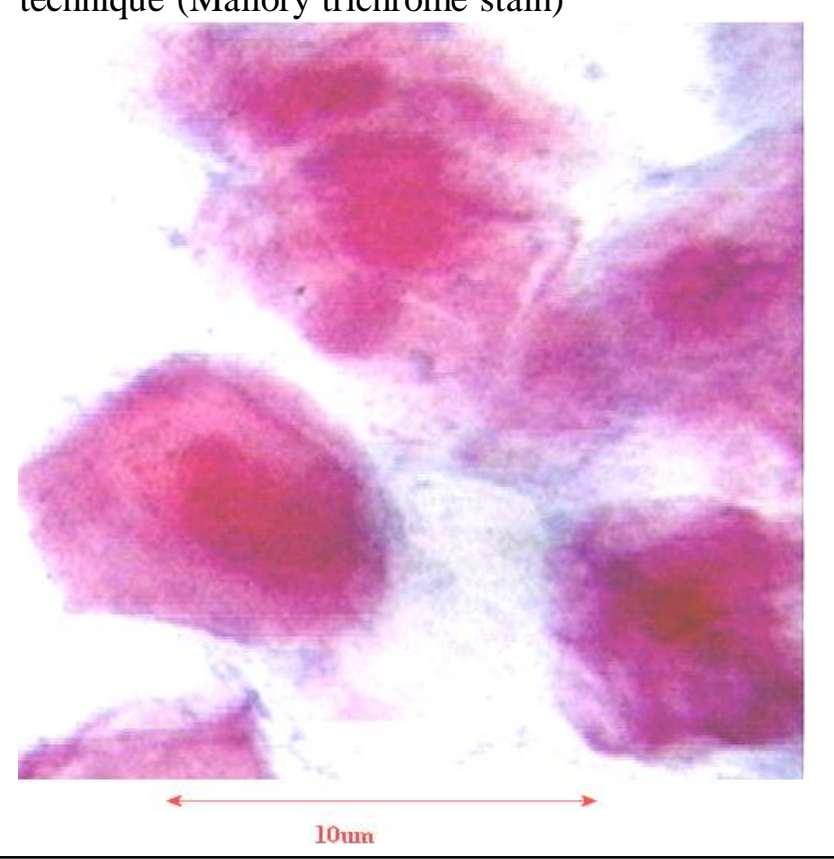

Figure 6-Computerized photomicrograph of adult albino rat hepatocytes prepared by paraffin technique (Hx and E. stain)

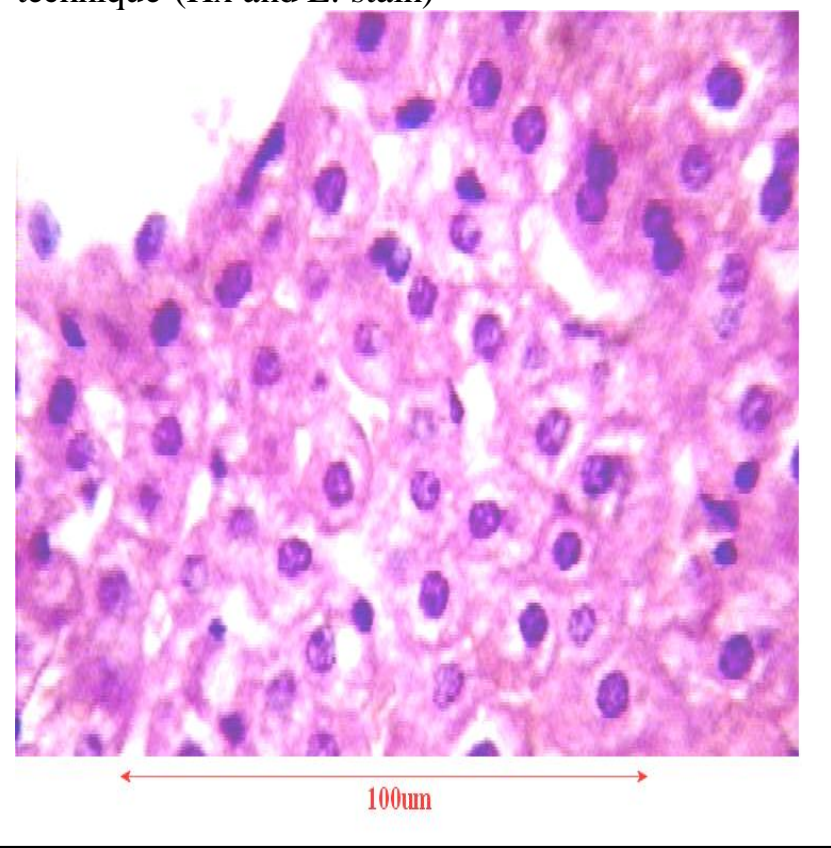




\section{Bassem S. Kotb}

Figure 7-Computerized photomicrograph of transverse section in normal female albino rat uterus prepared by paraffin technique (Mallory trichrome stain)

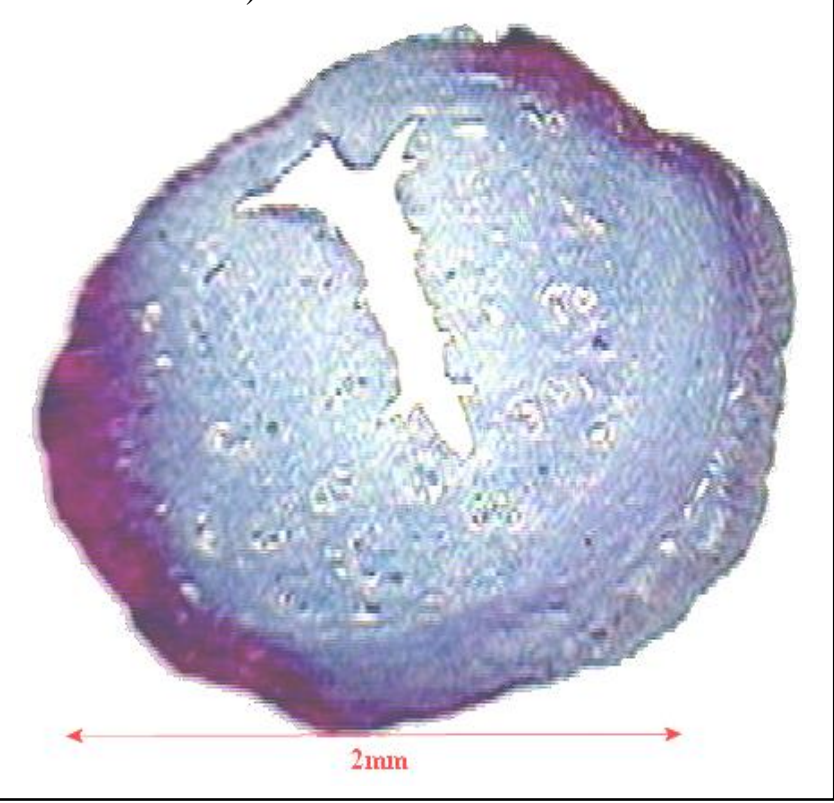

Figure 8-Computerized photomicrograph of transverse section in normal female albino rat uterus prepared by frozen technique (Mallory trichrome stain)

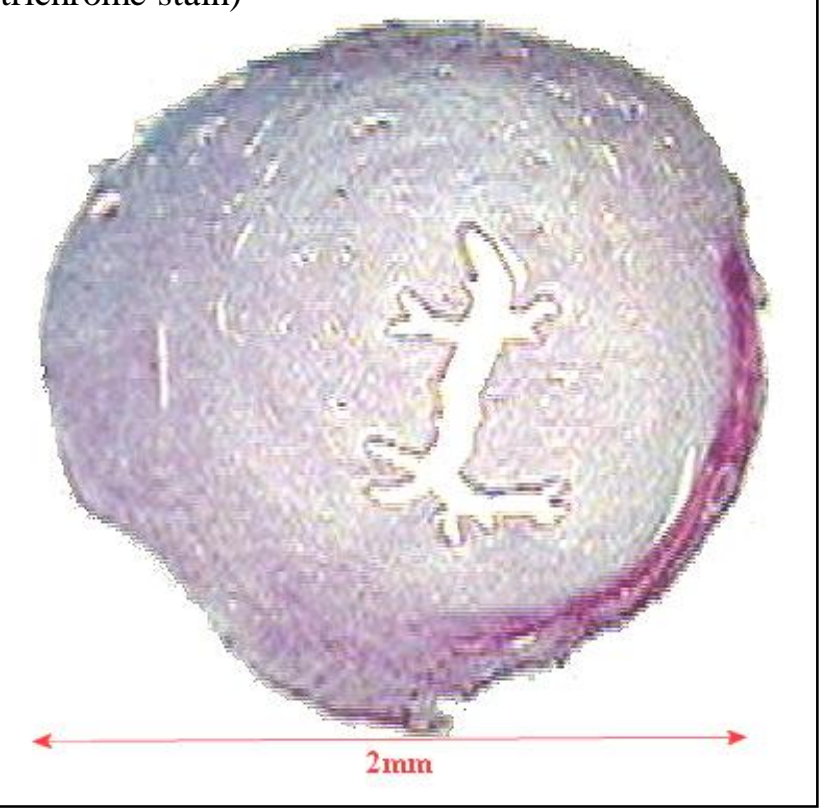

Figure -9 The effect of histological techniques on diameter and area of human RBCs

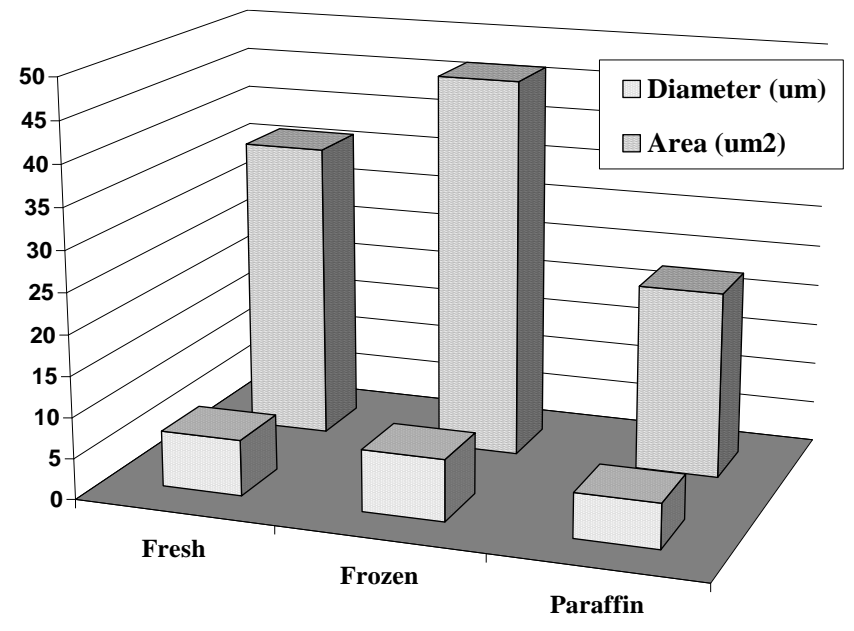

- Albino rats hepatocytes morphometric results:

The effect of histological techniques on the morphometric results of albino rat hepatocytes are summarized in tables 3 - 4 and figures 4-6 and figures 10-11 


\section{Comparative Study On The Effect}

Table-3The effect of histological techniques on rat hepatocytes cell and nuclear diameters

\begin{tabular}{|c|c|c|c|c|c|c|}
\hline & \multicolumn{2}{|l|}{ Fresh } & \multicolumn{2}{|l|}{ Frozen } & \multicolumn{2}{|l|}{ Paraffin } \\
\hline & Cell & Nucleus & Cell & Nucleus & Cell & Nucleus \\
\hline Mean & 10.61 & 5.09 & 13.09 & 5.81 & 7.31 & 3.47 \\
\hline SD & 2.64 & 0.7 & 3.26 & 0.79 & 0.98 & 0.87 \\
\hline SEM & 1.98 & 1.13 & 2.4 & 1.29 & 1.80 & 0.83 \\
\hline Min & 6.8 & 3.67 & 8.38 & 4.19 & 5.26 & 1.81 \\
\hline Max & 15.92 & 6.11 & 19.64 & 6.99 & 9.37 & 5.1 \\
\hline \multirow[t]{2}{*}{$\mathrm{t}$ - Test } & & & Fresh vs. Frozen & $\begin{array}{l}\text { Fresh vs. } \\
\text { Frozen }\end{array}$ & Fresh vs. Paraffin & $\begin{array}{l}\text { Fresh vs. } \\
\text { Paraffin }\end{array}$ \\
\hline & & & 0.012 & 0.004 & $6.15 E-06$ & 1.27E-07 \\
\hline$p$ - value & & & $p<0.05$ & $p<0.005$ & $p<0.001$ & $p<0.001$ \\
\hline Sign. & & & Sign. Inc. & Sign. Inc. & Sign. Dec. & Sign. Dec. \\
\hline Change\% & & & 23.37 & 14.29 & 31.12 & 31.78 \\
\hline
\end{tabular}

Figure-10-The effect of histological techniques on rat hepatocytes cell and nuclear diameters

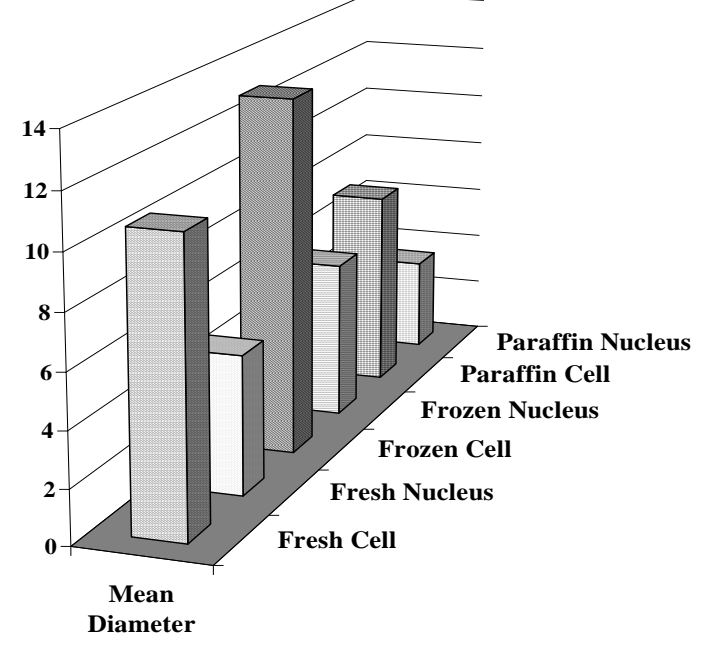

Table-4- The effect of histological techniques on rat hepatocytes cell and nuclear areas

\begin{tabular}{|c|c|c|c|c|c|c|}
\hline & \multicolumn{2}{|l|}{ Fresh } & \multicolumn{2}{|l|}{ Frozen } & \multicolumn{2}{|l|}{ Paraffin } \\
\hline & Cell & Nucleus & Cell & Nucleus & Cell & Nucleus \\
\hline Mean & 239.3 & 49.31 & 295.21 & 56.35 & 187.68 & 43.61 \\
\hline SD & 68.77 & 13.04 & 84.83 & 14.90 & 53.93 & 11.53 \\
\hline SEM & 76.67 & 9.64 & 94.57 & 11.01 & 60.12 & 8.52 \\
\hline Min & 112.46 & 26.5 & 138.73 & 30.28 & 88.2 & 23.43 \\
\hline Max & 345.94 & 74.43 & 426.77 & 85.07 & 271.32 & 65.83 \\
\hline \multirow[t]{2}{*}{ T-Test } & & & Fresh & Fresh & Fresh vs. Paraffin & $\begin{array}{l}\text { Fresh vs. } \\
\text { Paraffin }\end{array}$ \\
\hline & & & 0.028 & 0.120 & 1.2E-02 & $1.51 \mathrm{E}-01$ \\
\hline$p$ - value & & & $p<0.05$ & $p>0.05$ & $p<0.05$ & $p>0.05$ \\
\hline Sign. & & & Sign. Inc. & NS & Sign. Dec & NS \\
\hline Change & & & 23.37 & 14.29 & 21.57 & 11.56 \\
\hline
\end{tabular}




\section{Bassem S. Kotb}

Figure-11-The effect of histological techniques on rat hepatocytes cell and nuclear areas

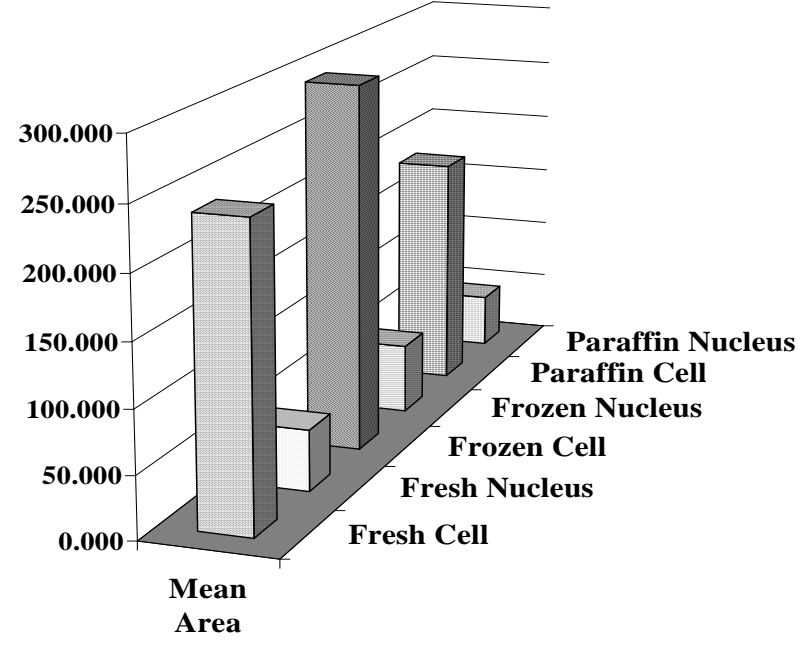

- Albino rats uterine morphometric results:

The effect of histological techniques on the gross perimeter and area, uterine cavity (area and diameter), and area percent of uterine collagen and muscle fibers are summarized in tables 5 - 7 and figures 7-8 and figures 13-16

Table-5-The effect of histological techniques on the perimeters of uterus and uterine cavity of the albino rats

\begin{tabular}{|c|c|c|c|c|}
\hline & \multicolumn{2}{|c|}{ Lumen } & \multicolumn{2}{|c|}{ Uterus } \\
\hline & Paraffin & Frozen & Paraffin & Frozen \\
\hline Mean(um) & 2312.57 & 1798.59 & 6039.32 & 5360.95 \\
\hline SD & 250.76 & 125.50 & 573.44 & 370.70 \\
\hline SEM & 79.30 & 39.69 & 181.34 & 117.23 \\
\hline Min & 2001.39 & 1569.72 & 5381.52 & 4910.53 \\
\hline Max & 2776.32 & 1993.88 & 7023.32 & 5903.92 \\
\hline \multirow{2}{*}{ T-Test } & & $1.72 \mathrm{E}-05$ & & $5.64 \mathrm{E}-03$ \\
\hline & & Frozen vs. Paraffin & & Frozen vs. Paraffin \\
\hline$p$-Value & & $p<0.001$ & & $p<0.01$ \\
\hline Sign & & Sig. Dec. & & Sig. Dec. \\
\hline Change\% & & 22.23 & & 11.23 \\
\hline
\end{tabular}

Figure-12-The effect of histological techniques on the perimeters of uterus and uterine cavity of the albino rats

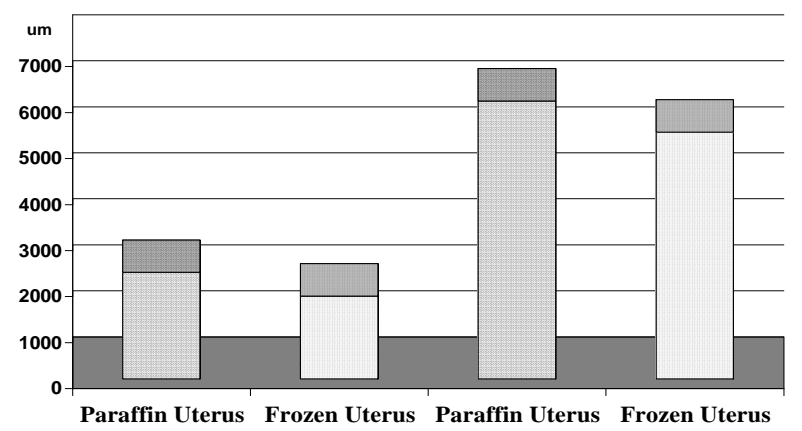




\section{Comparative Study On The Effect}

Table 6-The effect of histological techniques on the areas of uterus and uterine cavity of the albino rats

\begin{tabular}{|c|c|c|c|c|}
\hline & \multicolumn{2}{|c|}{ Lumen } & \multicolumn{2}{|c|}{ Uterus } \\
\hline & Paraffin & Frozen & Paraffin & Frozen \\
\hline Mean $\left(u^{2}{ }^{2}\right)$ & 466948.34 & 416174.07 & 1484663.08 & 1385010.00 \\
\hline SD & 20692.96 & 26651.98 & 30261.08 & 7276.83 \\
\hline SEM & 6543.69 & 8428.10 & 9569.40 & 2301.14 \\
\hline Min & 431086.00 & 384858.00 & 1406464.00 & 1377098.00 \\
\hline Max & 494772.00 & 464875.00 & 1510042.00 & 1399983.00 \\
\hline \multirow[b]{2}{*}{ T-Test } & & 1.57E-04 & & 7.37E-09 \\
\hline & & Frozen vs. Paraffin & & $\begin{array}{ll}\text { Frozen } & \text { vs. } \\
\text { Paraffin } & \\
\end{array}$ \\
\hline$p$-Value & & $\mathrm{p}<0.001$ & & $\mathrm{p}<0.001$ \\
\hline Sign & & Sig. Dec. & & Sig. Dec. \\
\hline Change\% & & 10.87 & & 6.71 \\
\hline
\end{tabular}

Figure-14 -The effect of histological techniques on the areas of uterus and uterine cavity of the albino rats

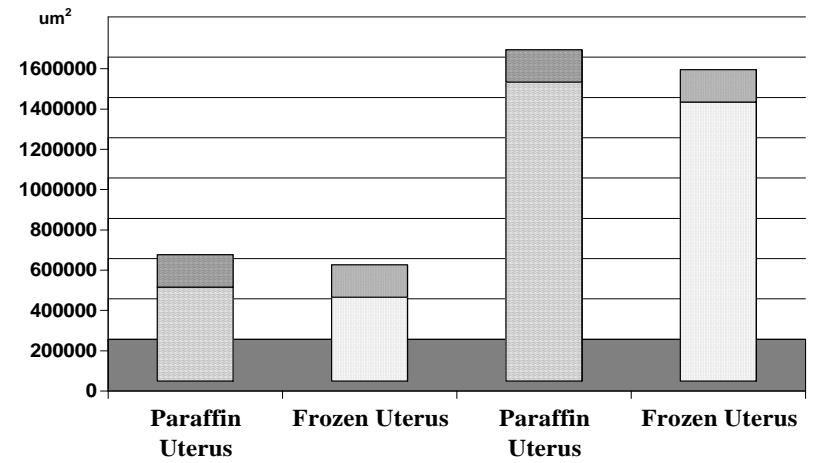

Table-7The effect of histological techniques on the uterine collagen and muscle fibers percentage areas of the albino rats

\begin{tabular}{|c|c|c|c|c|c|c|}
\hline & \multicolumn{3}{|c|}{ Paraffin } & \multicolumn{3}{|c|}{ Frozen } \\
\hline & $\begin{array}{l}\text { Muscl } \\
\text { es }\end{array}$ & Collagen & M/C Ratio & Muscles & Collagen & M/C Ratio \\
\hline Mean\% & 0.30 & 0.31 & 0.97 & 0.23 & 0.47 & 0.50 \\
\hline SD & 0.01 & 0.03 & 0.13 & 0.01 & 0.05 & 0.07 \\
\hline SEM & 0.00 & 0.01 & 0.04 & 0.00 & 0.02 & 0.02 \\
\hline Min & 0.28 & 0.26 & 0.82 & 0.21 & 0.38 & 0.39 \\
\hline Max & 0.33 & 0.35 & 1.16 & 0.25 & 0.57 & 0.60 \\
\hline \multirow[t]{2}{*}{ T-Test } & & & & Frozen vs. Paraffin & Frozen vs. Paraffin & $\begin{array}{c}\text { Frozen vs. } \\
\text { Paraffin }\end{array}$ \\
\hline & & & & $8.2 \mathrm{E}-10$ & $2.8 \mathrm{E}-07$ & 4.7E-09 \\
\hline$p$-Value & & & & $p<0.001$ & $p<0.001$ & $p<0.001$ \\
\hline Sign & & & & Sig. Dec & Sig. Inc. & Sig. Dec \\
\hline $\begin{array}{l}\text { Change } \\
\%\end{array}$ & & & & 23.99 & 49.44 & 48.95 \\
\hline
\end{tabular}

$*$ Mean $\%=($ collagen or muscle fibers area) / whole uterine area) $* 100$

*Comparison was done on frozen muscle vs. paraffin muscle .

$* \mathrm{M} / \mathrm{C}$ ratio $=\mathrm{XXX}$ muscle $/ \mathrm{XXX}$ collagen

$* \mathrm{M} / \mathrm{C}$ Comparison was done on frozen $\mathrm{M} / \mathrm{C}$ vs. paraffin $\mathrm{M} / \mathrm{C}$ 


\section{Bassem S. Kotb}

Figure-14 The effect of histological techniques on the uterine collagen and muscle fibers percentage areas of the albino rats

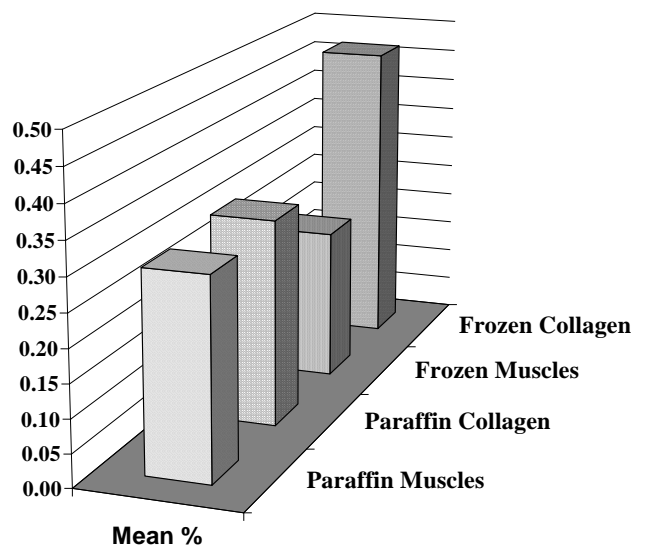

Figure-15 The effect of histological techniques on the ratio uterine muscle to collagen fibers ratio of the albino rats

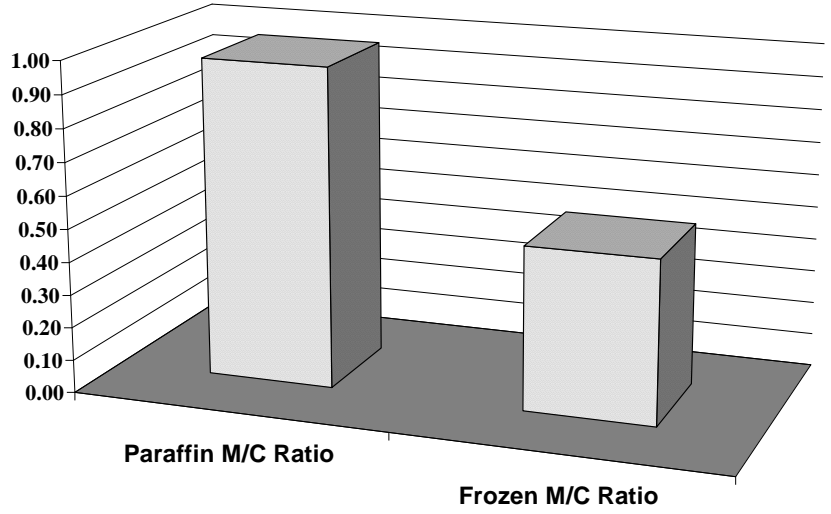

\section{Discussion}

The present study was planned to demonstrate the possible effect of the histological technique used on histol ogical Quantitation. Measuring of hum an red blood corpuscles diameters and areas in fresh preparation was consid ered as a starting point in the study, and to evaluate the image analyzer measuring quality. The obtained data were in an acceptable normal control range (RBCs diameter was 6.84 \pm 0.66 um, and area $36.29 \pm 5.59 \mathrm{um}^{2}$ ).

The diameter and area significantly increased after freezing technique $(\mathrm{p}<0.001) \quad\left(7.50 \mathrm{um} \pm 0.51\right.$ and $46.4 \mathrm{um}^{2}$ \pm 4.78 respectively), and decreased in paraffin technique $(5.47 \mathrm{um} \pm 0.73$ and $22.75 \mathrm{um}^{2} \pm 3.71$ respectively). The variation in RBCs diameters was $8.85 \%$ in frozen and $-20.04 \%$ in paraffin, while area was affected by $27.86 \%$ in frozen results and $-37.30 \%$ in paraffin.

Study of rat hepatocytes cell diameters showed statistically signify cant changes $(7.31 \mathrm{um} \pm 2.64,13.09 \mathrm{um}$ \pm 3.26 and $10.61 \mathrm{um} \pm 0.98$, in fresh, frozen and paraffin respectively).

Similar finding was observed in hepatocytes nuclear diameter (5.09um \pm $0.7,5.81 \mathrm{um} \pm 0.79$ and $3.47 \mathrm{um} \pm 0.87$, in fresh, frozen and paraffin respectively). Also, the mean hepatocytes cell area 


\section{Comparative Study On The Effect}

was changed $\left(239.3 \mathrm{um}^{2} \pm 68.77,295.21\right.$ $\mathrm{um}^{2} \pm 84.83$, and $187.68 \mathrm{um}^{2} \pm 53.93$ in fresh, frozen and paraffin respectively). While the mean hepatocytes nuclear area was not statistically affected, p>0.05, (49.31um ${ }^{2} \pm 13.04,56.35 \mathrm{um}^{2} \pm$ 14.90, and $43.61 \mathrm{um}^{2} \pm 11.53$, in fresh, frozen and paraffin respectively)

The frozen and paraffin histological techniques also caused a change in, the gross uterine perimeter and area, and uterine wall (perimeter and area). The mean paraffin uterine area and perim eter was $1484663.08 \mathrm{um}^{2} \pm 30261.08$ and $6039.32 \mathrm{um} \pm 573.44$, respectively) while in frozen was $1385010.00 \mathrm{um}^{2} \pm$ 7276.83 and 5360.95 um \pm 370.70, respectively). Regards uterine cavity, the mean paraffin area and perimeter was $466948.34 \mathrm{um}^{2} \pm 20692.96$ and 2312.57 um \pm 250.76 , respectively) while in frozen was $416174.07 \mathrm{um}^{2} \pm$ 26651.98 and 1798.59 um \pm 125.50 , respectively).

During the evaluation of total uterine (collagen, muscle fibers and their ratio) as area percent, a statistically significant variation was observed betw -een paraffin and frozen uterine sections. In paraffin section percentage of muscle fibers was $30 \% \pm 1 \%$, collagen fibers $31 \% \pm 3 \%$ and the ration of muscle fibers to collagen fibers was $0.97: 1.0$, while in frozen sections the muscle fibers percent decreased to $23 \%$ $\pm 1 \%$, the collagen fibers percent increased to $47 \% \pm 1 \%$ and the ratio of muscle to fibers was $1: 2$

The change in cell morphometric analysis is agreed with researches of Pentilla et al., (1975), SchmidSchonbein et al., (1980), Gerdes et al., (1982), Hanstede and Gerrits (1983), Reith et al., (1984) , Wegiel et al., (1989), Miller and Meyer (1990) and Gilbert and Parmley (1998).

Pentilla et al., (1975), stated that, during fixation, tissues commonly change in volume and the mechanisms involved are ill-understood, and various factors have been suggested, including inhib ition of respiration, changes in memb rane permeability or in ion transport through the membranes. The subseq uent dehydration and embedding will also bring about further changes in volume. Ideally, these changes should cancel each other out to give no net change. Tissues fixed in formaldehyde and embedded in paraffin wax shrink by 33 per cent. The nuclei in frozen sections are usually bigger than those of the same tissue which has been subjected to conventional preparation, but these changes are relatively small compared to other organelles. Prolonged fixation in formalin can give rise to secondary shrinkage. Injured cells swell or shrink to a different extent to normal cells in chemical fixatives.

Pentilla et al., (1975), also reported that some intracellular substances such as collagen swell when they are fixed and besides these volume changes which occur during fixation, the net change in volume of the various compo -nents of tissue should be considered through to the section on the slide. This is of importance when slides are compared with living tissue, for example in histometric studies.

Schmid-Schonbein et al., (1980), studied the possible artifacts due to preparation of the cells for transmission electron microscopy, with a detailed comparison with light microscopy. The quantitative morphometric parameters of leukocyte functions were include the diameter, volume, and membrane area of the cells and their nuclei in the undeformed state. A stereological meth -od was used to obtain these quantities from transmission electron microscopy of random sections through human white blood cells (neutrophils, lympho cytes, monocytes, and eosinophils). The 
results showed that undeformed white cells in isotonic solution are spherical with many membrane folding and had a significantly smaller diameter than that measured on blood smears and a method of chemical fixation was empl oyed so that the shrinkage due to fixation of the cells was below the resolution of light microscopic measure -ments. Further, it was shown that all leukocytes, including lymphocytes, had much more membrane area than was needed to cover their volumes, and this membrane area remained constant when the cell was hypotonically swollen .

Gerdes et al., (1982) studied the morphometric changes occurred in an isolated cardiac myocytes through the entire procedure after fixation with isoosmolar glutaraldehyde and investigated these changes, adhering of the cells to glass cover slips of Sykes Moore cham bers and photographed after each step of processing for transmission electron microscopy. The cellular dimension changes were determined by tracing individual isolated myocytes after each step of the procedure with a sonic digit izer. Significant cell volume changes occurred after osmium (16\% swelling), post osmium wash (10\% swelling), and uranyl acetate (25\% shrinkage).

Hypertonic aldehyde solutions resulted in cellular shrinkage during fixation not found with isotonic solutions. Changes in cell crosssectional area rather than length were largely responsible for altered cell volumes during any given phase of processing. The results indicated that, although cell volume changes occur during processing, final cell dimensions of embedded cells were not different from unfixed cells.

Hanstede and Gerrits (1983), described the morphometric changes of the liver samples, in the course of fixation, dehydration, infiltration and embedding in different mixtures of water-soluble plastics (glycolmeth acrylate (GMA) and the commercially available material JB4). Buffered formaldehyde fixation did not produce significant morphometric changes in the liver specimens. Dehydration obviously affects the volume of the liver specimen (linear shrinkage about 9.3\%). The dehydration is followed by an infiltra tion phase. During this phase a slight swelling (linear, 2-5\%) occurs. Correction factors must be used in morphometric and stereological investigations.

Reith et al., (1984) studied the influence of perfusion versus immersion fixation with cacodylate buffered gluta raldehyde, osmium or glutaraldehyde immersion fixation with two vehicles, phosphate and cacodylate on cellular and sub cellular structure of animal hepatocytes. There were $15 \%$ increase in the volume of hepatocytes (mainly their cytoplasm), and 30\% increase after immersion fixation in osmium in comparison to perfusion fixation. The mitochondrial enlargement was particu larly displayed in the organelles, average profile area, being more than doubled $(211 \%)$ in immersion fixation. Similarly high profile enlargements $(150 \%)$ were also found after osmium immersion fixation. Changes in nuclei were minor compared to the cytoplasm. Wegiel et al., (1989) reported that the estimation of the volume of the rat substantia nigra and striatum during the first half year of life fixed in $8 \%$ formaldehyde in at $20 \mathrm{C}^{0}$ for $48 \mathrm{hrs}$ produced rapid increase of the brain weight and volume up to $52 \%$ of that of the fresh brain followed by slow decrease of brain weight of about 1$3 \% / 24$ hrs. Dehydration in ethyl alcohol produced violent decrease of brain volume and weight (from $32 \%$ up to $39 \%$ of the fresh brain weight). Clearing 


\section{Comparative Study On The Effect}

in methyl bensoesane increases again the brain weight by a few percentage. So the histological procedure causes error size, more pronounced in fetal rat brain and in brain of 1-2-day-old rats.

Miller PL and Meyer TW. (1990); studied the effect of tissue preparation on glomerular volume in normal rats and the values for glomerular volume obtained in paraffin-embedded tissue were approximately $40 \%$ lower than values for glomerular volume obtained in methacrylate-embedded tissue from the same kidneys. The morphometric studies showed reduction in glomerular volume in immersion-fixed tissue associ -ated with lowered values of peripheral capillary wall surface area and reduced mean capillary radius compared with perfusion-fixed tissue.

Gilbert and Parmley (1998); reported that, neutrophil cells which cryofixed or fixed in dimethyl sulfoxide-cryofixation -freeze-substitution processing were significantly rounder, $27-30 \%$ larger in cell volume than neutrophil cells which had fixed in glutaraldehyde and post fixation osmium tetroxide. The increase in cell volume in cryofixed cells did not appear to be due to abnormal cell swe lling, since membranes, nuclear envel ope, and mitochondrial cristae were more intact than in glutaraldehyde and post fixation osmium tetroxide cells. The morphometric data of the nuclear compartment was $22 \%$ smaller, while the cytoplasm (and its associated compartments) was $29 \%$ smaller in glutaraldehyde and post fixation osmium compared to cryofixed or fixed in dimethyl sulfoxide - cryofixation freeze - substitution processing neutrophils .

\section{References:}

1. Drury RA and Walington EA (1980): Carleton' Histology Techniques. $5^{\text {th }}$ Ed. Oxford Univ. Press. Oxford.
2. Gerdes AM, Kriseman $\mathbf{J}$ and Bishop SP. (1982): Morphometric study of cardiac muscle: the problem of tissue shrinkage. Lab Invest Mar;46(3):271-4

3. Gilbert CS and Parmley RT. (1998): Morphology of human neutrophils: a comparison of cryofi xation, routine glutaraldehyde fixat ion, and the effects of dimethyl sulfoxide. Anat Rec Oct;252(2): 254-63

4. Hanstede JG and Gerrits PO. (1983) : The effects of embedding in water-soluble plastics on the final dimensions of liver sections. $\mathbf{J}$ Microsc Jul;131 (Pt 1):79-86

5. Miller PL, and Meyer TW.(1990): Effects of tissue preparation on glomerular volume and capillary structure in the rat. Lab Invest Dec;63(6):862-6

6. Pentilla A., McDowell E. M., and Trump B. F. (1975): Effects of fixation and post-fixation treatments on volume of injured cells. J. of Histochemistry and Cytochemistry, 22: 251-270

7. Reith A, Kraemer $M$ and Vassy J. (1984): The influence of mode of fixation, type of fixative and vehic les on the same rat liver: a morpho metric/ stereological study by light and electron microscopy. Scan Electron Microsc; (Pt 2): 645-51

8. Schmid-Schonbein GW, Shih YY and Chien S. (1980): Morphometry of human leukocytes. Blood Nov;56(5):866-75

9. Wegiel J, Medynska E, Dziedziak W, Szirkowiec-Gmurczyk $W$ and Dymecki J. (1989): Effect of histological techniques on the volume and weight of various brain structures of rats at the early stages of life. Neuropatol Pol ;27(2):279-b 94. 
دراسة مقارنة عن تأثير استخدام بعض التقتيات النسيجية على التحليل

$$
\begin{aligned}
& \text { الكمى الثكلى لدفي } \\
& \text { د/ باسم سعيد قطب الطب } \\
& \text { أستاذ مساعد بكلية طب جامعة الأزهر - فرع عأسيوط }
\end{aligned}
$$

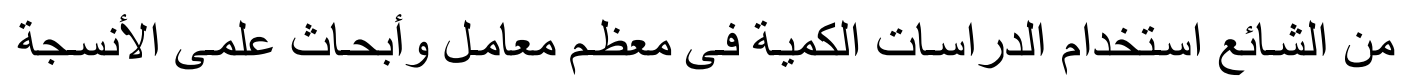

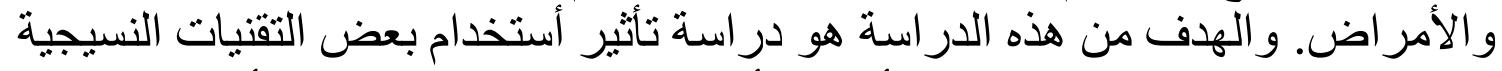

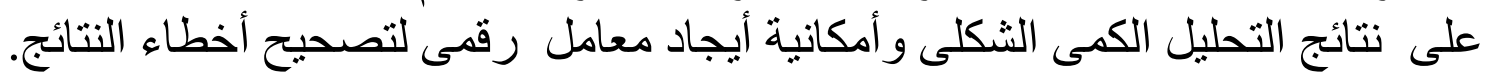

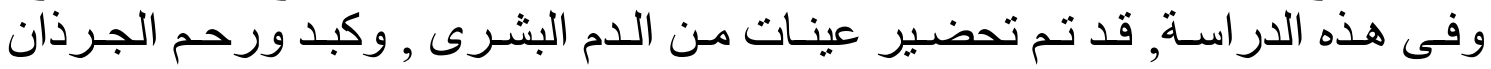

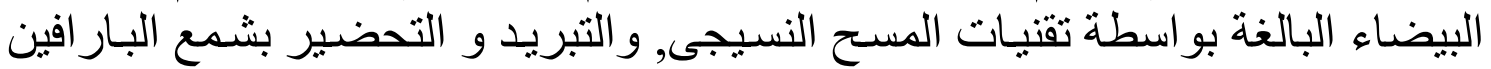

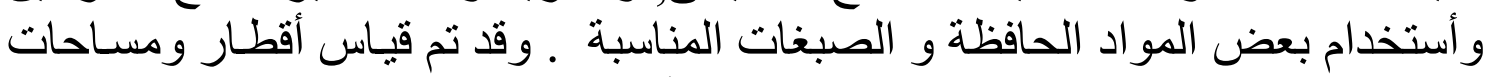

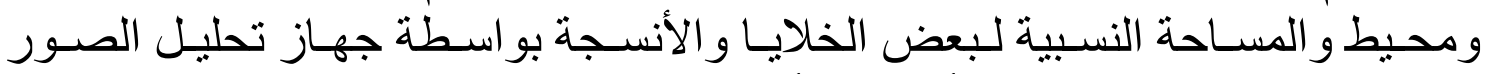

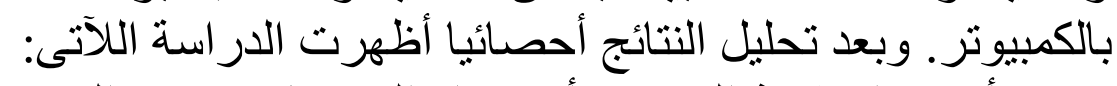

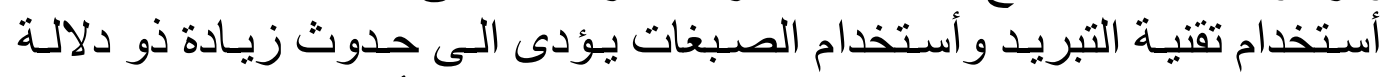

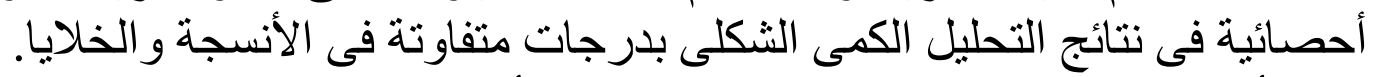

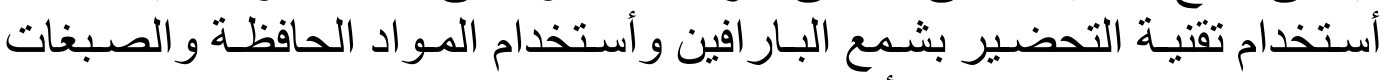

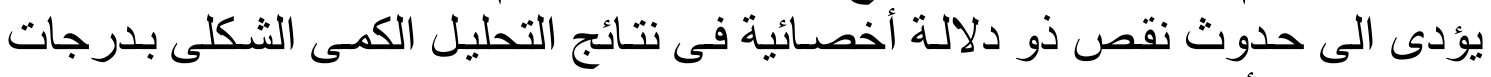
متفاوتة في الأنسجة و والخلايا. و جود تغيير ات فى نتائج نسبة محتويات الانيات الأنسجة من العضـلات و الألياف عند تغيير التقنية النسيجية المستخدمة.

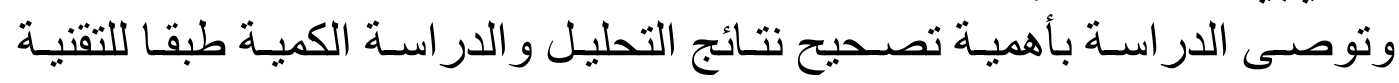
النسيجية المستخدمة و النسيج الذى تم دراسته قبل تقييم النتائج وتفسير ها. 